\title{
Performance Comparison of Surface Waterproofing Products with Various Chemical Compositions on Brick Masonry
}

\author{
Henry Zhu ${ }^{\mathrm{a}, \mathrm{b}}$, Dina D’Ayala ${ }^{\mathrm{a}}$, Yasemin D Aktas ${ }^{\mathrm{a}, \mathrm{b}}$ \\ a Department of Civil Environmental and Geomatic Engineering (CEGE),UCL, London, UK \\ b UK Centre for Moisture in Buildings (UKCMB), London, UK
}

\begin{abstract}
Moisture risk in building systems is one of the major concerns affecting the durability of building envelopes and indoor comfort. Surface waterproofing products are a common and simple methods to enhance the moisture performance of masonry buildings. However, the various chemical compositions of these products can lead to very different performance under exposure. This paper focus on the comparison and discussion of the different level of impact of surface waterproofing products with various chemical compositions on the performance of brick masonry substrate through a series of benchtests on small scale specimens to test water vapour transmission, hydrophobicity and liquid water absorption. Four different types of waterproofing products were selected, along with 3 brick types common in the 50 s and 60 s to be representative of the majority of the UK building stock. Results show that the combined outcome of the three tests is sufficient to identify the clearly the effectiveness of the products in improving waterproofing while ensuring vapour transmission. It also shows that it is essential to use specimens reproducing the masonry fabric rather than samples of the individual materials.

Peer-review under the responsibility of the organizing committee of the ICMB21.
\end{abstract}

Keywords: waterproofing, water repellence, surface treatment, brick masonry, water vapour transmission, hydrophobicity, absorption

\section{Introduction and background}

Masonry is the most common construction method representing $91 \%$ of all homes in the UK. Many of them have no moisture proof treatment and localised material damage accumulated during service life makes them vulnerable to moisture ingress. Moisture ingress over time causes damage to both fabric and structure, reduces indoor thermal comfort and energy efficiency, and increases susceptibility to biodeterioration, which can lead to poor health and wellbeing. Surface waterproofing products have shown great potential as a method of improving the moisture ingress dynamics in walls. Research on the properties of treated brick and mortar specimens shows a wide range of performances of surface waterproofing products depending on their chemical base and substrate materials (Aktas et al., 2021). Esteves et al., (2019) investigated different types of hydrophobic treatments on various building materials concluding that the treatments reduced water ingress but impacted on the drying speed and water vapour transmission, while Soulios et al. (2020)'s study on silicon-based water repellents confirmed improvements in water resistance on brick and mortar with minimal impact on the water vapour permeability. Slapøet al. (2017) tested full brick masonry walls under WDR exposure found that surface water repellents are unable to improve water resistance, while Hansen et al. (2018) tested on solid masonry walls, moisture ingress reduced significantly on treated walls under exposure, especially on silane-treated walls. In this study, after an initial market research, four representative waterproofing products were selected for testing. These include silane/siloxane blend liquid and cream, an acrylic-based liquid and a stearate-based liquid. The products were applied to three brick types, representing UK cavity walls building stock of the 50s and 60s. The objective is to determine the hygric behavior of brick masonry through small size bench tests of hydrophobicity, water absorption and water vapour transmission. The three tests represent first contact with water, wetting and drying, respectively, reproducing the whole moisture interaction cycle.

\section{Tests' design and procedure}

2.1. Hydrophobicity test. The hydrophobicity test follows BS ISO 19403-2:2017. By measuring the contact angle of the drop with the treated surface, representing the surface tension and the surface free energy of the drop, it provides a quantitative basis for the "wettability" of the surface. Higher contact angles mean higher hydrophobicity, lower wettability. Measurements were taken automatically with the DSA100 equipment. Temperature and relative humidity were controlled at $23 \pm 2{ }^{\circ} \mathrm{C}$ and $50 \pm 5 \% \mathrm{RH}$. The flat surfaces of 15 specimens, 3 for each brick types untreated or treated with one of the 4 different surface waterproofing products, were dosed and with 12 water drops on different parts of the surface and measurements taken for each drop (Figure 1a).

2.2. Water absorption test. In the absorption test, three different types of specimens were used for each treatment: $100 \mathrm{~mm}$ mortar cubes, 215 x 102.5 x 65 mm standard dimension full bricks, 215 x 140 x 28 mm brick and purposely prepared small masonry specimens obtained by mortaring two sleeves of brick $28 \mathrm{~mm}$ deep cut from the external side face of a brick. Such specimens meet the EN ISO 15148:2002 requirement to use at least 3 specimens with a surface area over $100 \mathrm{~cm}^{2}$. All specimens were dried and stored then tested in a controlled environment at $22^{\circ} \mathrm{C}$ and $55 \% \mathrm{RH}$ following the requirements of the same standard. The water level was maintained at $5 \pm 2 \mathrm{~mm}$ above the bottom of the specimens during the test (Figure 1b). Duct tape and silicone were used to seal the edges and interfaces to make sure water was only absorbed through the surfaces of interest. Measurements of mass change were taken at $5 \mathrm{~min}, 20 \mathrm{~min}, 1 \mathrm{~h}, 2 \mathrm{~h}, 4 \mathrm{~h}, 6 \mathrm{~h}, 8 \mathrm{~h}, 10 \mathrm{~h}$ and $24 \mathrm{~h}$.

2.3. Water vapour transmission test- BS EN ISO 12572:2016 was used to measure water vapour transmission properties of 
masonry specimens. Specimens were preparade with sections of brick of $28 \mathrm{~mm}$ thickness, satisfying the standard' minimum thickness of $20 \mathrm{~mm}$. Couples of brick slices were mortared together with $10 \mathrm{~mm}$ joint and sealed into the top of a plexiglass box with aqueous saturated solution at bottom $(93 \pm 5 \% \mathrm{RH})$, representing the "wet cup" condition. The mass change of each specimen was measured every $24 \mathrm{~h}$ while kept in an environmental cabinet set at $23^{\circ} \mathrm{C}$ and $50 \% \mathrm{RH}$ for 72 continuous hours (Figure 1c).
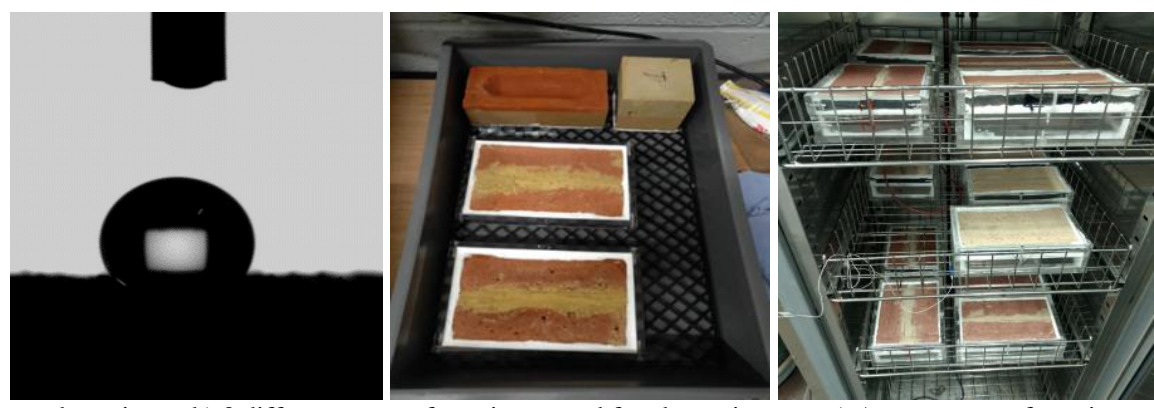

Figure 1: a) Water drop on treated specimen, b) 3 different types of specimen used for absorption test, c) Arrangement of specimens for vapour transmission test. 3. Test Results and conclusions

Figures $2 \mathrm{a}$ provides the average and standard deviation results of the hydrophobicity test. On untreated specimens water drops fully absorbed within 1-3 seconds, thus preventing the image capture to measure the contact angle (CA). Acrylic- and stearatebased products showed very similar results with consistent CAs for all brick types $\left(113.5^{\circ}\right.$ for the acrylic-based product and $114.1^{\circ}$ for the stearate-based product). Silane/siloxane blend cream treated specimens showed higher standard deviation and an average $\mathrm{CA}=102.8^{\circ}$ while silane/siloxane blend liquid showed lowest average CA of $91.9^{\circ}$. Figure $2 \mathrm{~b}$ shows the water vapour resistance factor $(\mu)$ for each brick type and treatment. Untreated specimens show brick type III has the lowest $\mu$. Treated specimens show lowest consistency for brick type I and highest for brick type III. Among treatments, the objective is to have as little increase in $\mu$ as possible with respect to untreated performance. The silane/siloxane blend liquid provides the highest impact on $\mu$. Acrylicbased liquids show lowest increase in $\mu$ followed by stearate-based liquid and the silane/siloxane cream for bricks I and III.
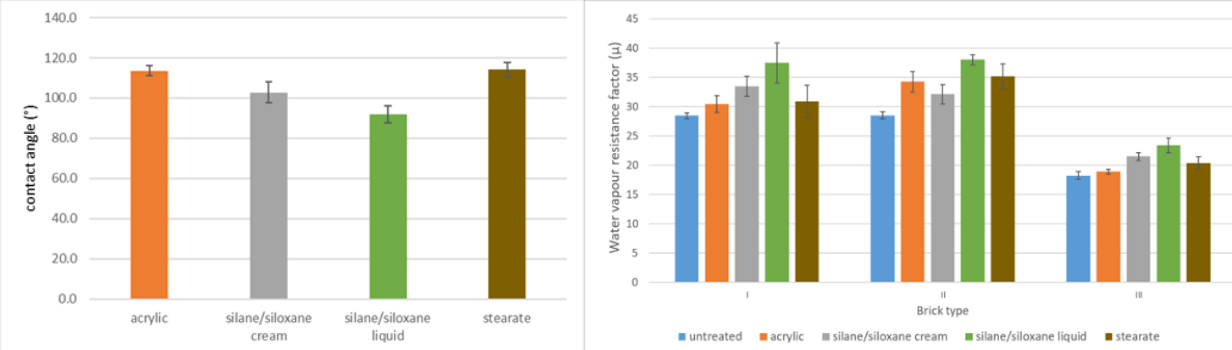

Figure 2: a) Average water contact angles for each treated specimen, b) Water vapour resistance factor $(\mu)$ of specimens with different brick types and treatments Brick

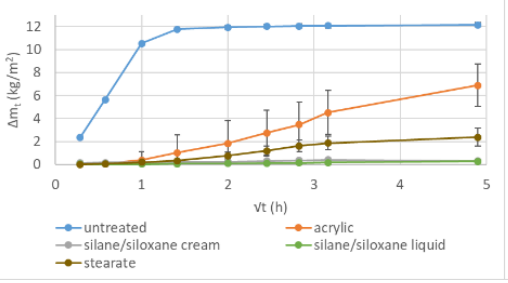

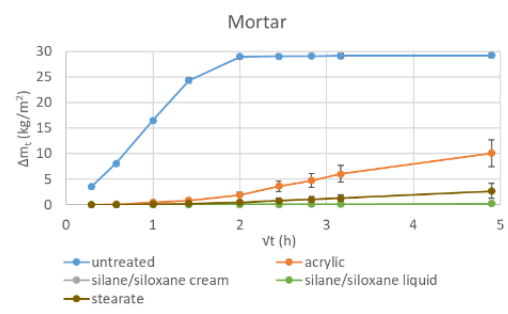
Masonry specimens

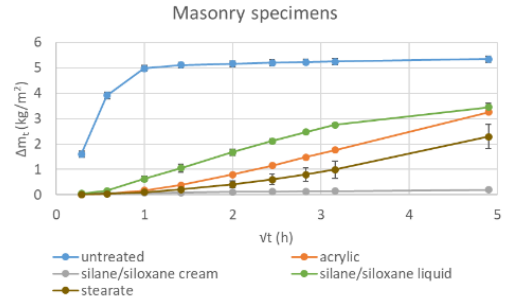

Figure3: Water absorption coefficient variations of brick, mortar and masonry specimens

Absorption tests are computed as increase of mass per unit of surface exposed to water $\left(\Delta \mathrm{m}_{\mathrm{t}}\right)$ in Figure 3 . Each data point is an average of 3 test results for each type of material and treatment, using brick type III. Untreated bricks and masonry specimens reach constant $\Delta \mathrm{m}_{\mathrm{t}}$ in about $2 \mathrm{~h}, 4 \mathrm{~h}$ for mortar specimens. Of the treated samples, the acrylic-treated specimens have the highest total $\Delta \mathrm{m}_{\mathrm{t}}$, for brick and mortar, without reaching a constant value in $24 \mathrm{~h}$. Silane/siloxane blend cream treated specimens show a flat line with almost no water absorption over all three types of specimens. Silane/siloxane blend liquid-treated specimens show very similar performance compared to those treated with the cream on both brick and mortar, but the highest $\Delta \mathrm{m}_{\mathrm{t}}$ among all four waterproofing treatments for the masonry specimen. The performance of the stearate-based liquid is intermediate (for further details see Aktas et al., 2021).

The sequence of results from the three tests allows to determine that the acrylic product has the best response in terms of wettability and water vapor resistance, but the worst for absorption. On the other hand, the silane/siloxane cream provide the best response in terms of absorption and second best for water vapour resistance. Interestingly, the silane/siloxane liquid has the worst behaviour. As a result of these set of tests is possible to rank the products in terms of the best performance in protecting walls from wind driven rain impact. This study was conducted as part of the 'Waterproofing cavity walls to allow insulation in exposed areas' project (2017-20), funded by Department for Business, Energy and Industrial Strategy (BEIS). Full scale tests on cavity walls were conducted and reported in a twin paper in this conference in order to further elaborate on these results.

\section{References}

[1] Aktas, Y.D., Zhu, H., D'Ayala, D., Weeks, C. (2021) Impact of surface waterproofing on the performance of brick masonry through the moisture exposure life-cycle, Building and Environment 197, 107844, pp.1-13, doi: 10.1016/j.buildenv.2021.107844

[2] Esteves, C., Ahmed, H., Flores-Colen, I. \& Veiga, R., 2019. The influence of hydrophobic protection on building exterior claddings. Journal of Coatings Technology and Research

[3] Soulios, V., Hansen, E. J., Feng, C. \& Janssen, H., 2020. Hygric behavior of hydrophobized brick and mortar samples. Building and Environment, Volume 176, p. 106843.

[4] Slapø, F. et al., 2017. Masonry's Resistance to Driving Rain: Mortar Water Content and Impregnation. Buildings, Volume 7, pp. 1-16.

[5] Hansen, T. K., Bjarløv, S. P., Peuhkuri, R. H. \& Handen, K. K., 2018. Performance of hydrophobized historic solid masonry - Experimental approach. Construction and Building Materials, Volume 188, pp. 695-708. 